\title{
Monogamous sperm storage and permanent worker sterility in a long-lived ambrosia beetle
}

\author{
Shannon M. Smith ${ }^{1,2,6 \star}$, Deborah S. Kent ${ }^{3,6}$, Jacobus J. Boomsma ${ }^{4,5 \star}$ and Adam J. Stow ${ }^{2}$
}

The lifetime monogamy hypothesis claims that the evolution of permanently unmated worker castes always requires maximal full-sibling relatedness to be established first. The long-lived diploid ambrosia beetle Austroplatypus incompertus (Schedl) is known to be highly social, but whether it has lifetime sterile castes has remained unclear. Here we show that the gallery systems of this beetle inside the heartwood of live Eucalyptus trees are always inhabited by a single core family, consisting of a lifetimeinseminated mother, permanently unmated daughter workers, and immatures that are always full siblings to each other and their adult caretakers. Overall sex ratios are even. Males always disperse and only survive as stored sperm, but female offspring either disperse to mate and found their own colony or assume unmated worker roles, probably surviving for many years without any reproductive potential because tarsal loss precludes later dispersal. A well-supported Platypodinae phylogeny has allowed us to infer that parental monogamy evolved before a lifetime-unmated worker caste emerged, confirming the prediction that monogamy and full-sibling relatedness are necessary conditions for the evolution of such workers. The initially very challenging but ultimately long-term stable nesting habitat in live trees appears to have provided the crucial benefit/cost factor for maintaining selection for permanently sterile workers after strict monogamy and lifetime sperm storage had become established in this curculionid coleopteran lineage.

S ince the inception of inclusive fitness theory more than 50 years ago, there has been debate on the relative significance of relatedness versus the benefits and costs of reproductive altruism. Hamilton's rule predicts that reproductive altruism in families can evolve only when the productivity benefit $(b)$ of rearing siblings with relatedness $r$ exceeds the costs $(c)$ of foregone offspring of relatedness 0.5 (such that $r b>0.5 c)^{1}$. Within this general framework, three additional insights specify key conditions for the evolution of obligate eusociality with a permanent worker caste ${ }^{2,3}$. First, modelling has demonstrated that haplodiploidy is not unambiguously favourable for the evolution of unmated castes ${ }^{4-8}$. Second, comparative analysis established that the evolution of unmated workers is often preceded by the co-option of ancestral behavioural or morphological traits in the service of sib-rearing, so that sexual dimorphism for these ancestral traits typically predicts the sex of the evolutionarily derived permanent workers ${ }^{9,10}$. Third, strict lifetime parental monogamy was inferred to be a necessary (but not sufficient) condition for evolving irreversible adult phenotypes, being either inseminated breeders or unmated workers ${ }^{3,8,11,12}$.

Irrespective of ploidy, lifetime parental commitment allows consistent selection for further morphological elaborations once permanent caste commitment has evolved, analogous to metazoan germ-soma differentiation evolving from lifetime commitment of two gametes to a zygote ${ }^{12}$. This explains why just a handful of lineages-ants, corbiculate bees, vespine wasps and evolutionarily derived termites-achieved obligate eusociality, characterized by (barring secondary reductions) specialized reproductives and a lifetime unmated foraging/nursing caste ${ }^{12,13}$. Breeding is merely cooperative in the other, facultatively eusocial insect lineages. Here, the extent of reproductive division of labour varies widely, but breeder and helper phenotypes are never fixed for life for all colony members, and at least some helpers will retain the ability to mate and reproduce later in life $\mathrm{e}^{2,12-14}$.

The Australian ambrosia beetle Austroplatypus incompertus (Schedl) (Coleoptera: Curculionidae: Platypodinae) has unfertilized workers ${ }^{15}$, but its cryptic lifestyle means that few facts about its social organization, mating system and caste commitment have been quantified. It is possible that this ancient lineage ${ }^{16}$ represents a longer-lived facultatively eusocial system comparable to the phylogenetically independent ${ }^{17,18}$ haplodiploid Xyleborini ambrosia beetles (Curculionidae: Scolytinae) ${ }^{19}$. These beetles often have inbred offspring, and multiple generations of breeders per colony are possible. As in most other scolytine ambrosia beetles, their galleries are much shorter-lived than those of $A$. incompertus because they exploit dead or stressed trees ${ }^{20}$ where resources are easily accessible but galleries quickly succumb to fungus-garden infections, desiccation and other natural enemies ${ }^{21,22}$. Alternatively, because all other platypodid beetles studied have monogamous biparental gallery foundation and at least some offspring care ${ }^{20,23-25}, A$. incompertus could be the first example of obligate caste-based reproductive altruism in the Coleoptera, one that shares diploidy with the termites and exclusive female colony founding with the social Hymenoptera. However, social males being unknown in $A$. incompertus ${ }^{15}$ then begs the question of how colonies persist for several decades without some form of incestuous breeder succession.

\section{Results}

Founding $A$. incompertus females excavate galleries in live Eucalyptus trees ${ }^{26}$ that are later also occupied by new generations of females, along with larvae and eggs ${ }^{15}$. Their multi-branched horizontal gallery systems have been found in 19 species of Eucalyptus in eastern Australia ${ }^{27}$ (Fig. 1a). We investigated 468 gallery systems

'Hawkesbury Institute for the Environment, Western Sydney University, Richmond, Australia. ${ }^{2}$ Biological Sciences, Macquarie University, Sydney, Australia. ${ }^{3}$ Brierfield, New South Wales, Australia. ${ }^{4}$ Centre for Social Evolution, Department of Biology, University of Copenhagen, Copenhagen, Denmark. ${ }^{5}$ Department of Zoology, University of Oxford, Oxford, UK. ${ }^{6}$ These authors contributed equally: Shannon M. Smith, Deborah S. Kent

*e-mail: shannon.smith@mq.edu.au; jjboomsma@bio.ku.dk 

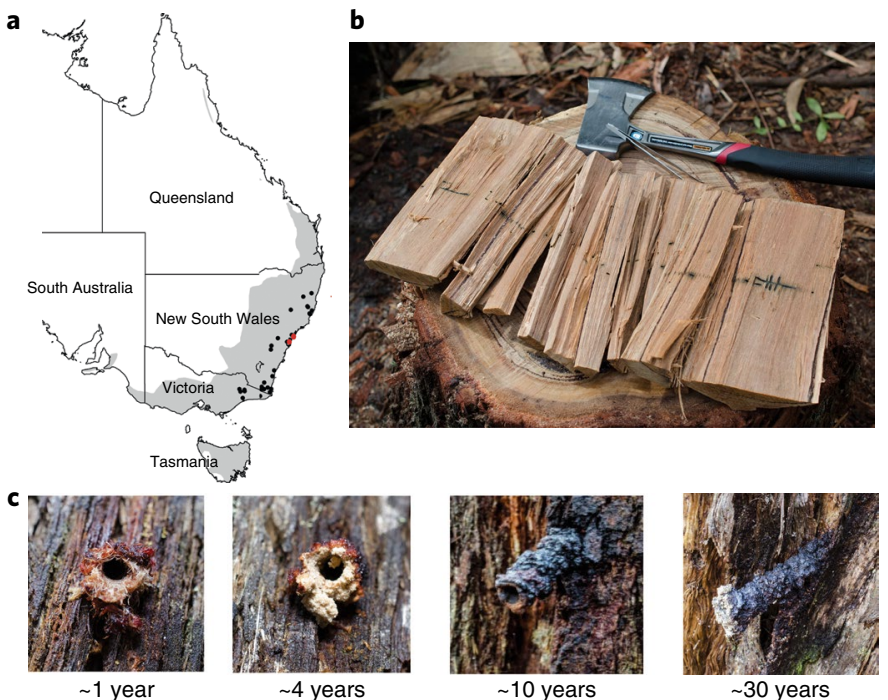

$\sim 1$ year

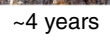

$\sim 10$ years

$\sim 30$ years

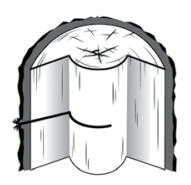

Single

foundress
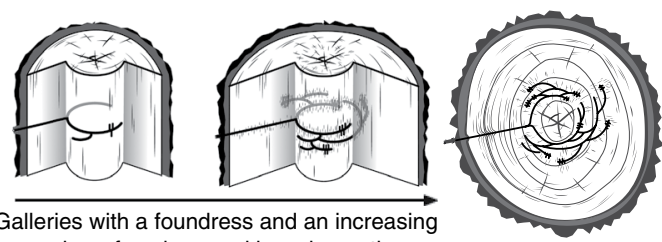

Galleries with a foundress and an increasing

Fig. 1 | Distribution, sampling and gallery phenology. a, A. incompertus gallery systems are found within live Eucalyptus trees in southeastern Australia. Black dots are recorded beetle occurrences and the shaded region indicates the approximate distribution of their 19 known host trees ${ }^{27}$. Sampling site locations are indicated in red. b. A billet of a felled Eucalyptus trunk of approximately $45 \mathrm{~cm}$ diameter at breast height with an exposed horizontal gallery system for further dissection with a hatchet/chisel to allow collection of beetles and brood and assessment of gallery phenology. c, Typical entrances of gallery systems ('kino' tubes) aged around 1, 4, 10 and 30 years, supplemented by representative drawings of the horizontal gallery systems and their vertical pupal chambers.

by either felling live trees or monitoring entrances and collecting emerging adults in situ (Fig. 1b and Supplementary Table 1). Gallery systems follow a predictable sequence of slow protracted growth, taking four years from gallery initiation by a lone foundress until dispersal of the first adult offspring (Figs. 1c and 2 and Supplementary Information). We destructively sampled galleries of all developmental stages outside the annual period in which adult offspring disperse (late March to early May) (Supplementary Table 1). Galleries contained 0-100 larvae and eggs and 1-13 adult female residents, distinguishable from adult females dispersing in other times of the year by the almost universal lack of tarsal segments (Fig. 3a,b, Supplementary Information and Supplementary Tables 2 and 3). Loss of tarsal segments (especially claws) makes it impossible to move around outside the confines of the gallery, so these females will never be able to reach any other gallery system ${ }^{15}$ (Supplementary Information).

Dissections of adults $(n=76)$ from from 16 colonies covering all developmental gallery stages (Fig. 1c) revealed that there was never more than one female that showed clear signs of having reproduced, that is, having both developed ovaries with visible oocytes or eggs, and a filled sperm storage organ (spermatheca; Fig. 3c,d). Nonreproducing residents, always with empty spermatheca and vestigial ovaries, were only found in galleries at least four years old, consistent with an earlier report ${ }^{15}$ (Fig. 2). The total number of broods per colony increased linearly with the number of resident females, with only a small non-significant quadratic term. This suggests that reproductive returns remain constant, with each unmated worker in the older colonies that we sampled raising a similar number of dispersing siblings each year (Fig. 4a). Under outbreeding (see below), A. incompertus should invest equally in dispersing males and females ${ }^{28}$, which was supported by our overall sex ratio estimate.
Using micro-cages (Supplementary Information), we collected 411 dispersing females and 418 males from 36 active colonies over five years, which produced a numerical ratio not significantly different from 1:1 $\left(\chi^{2}=0.059\right.$, d.f. $=1, P=0.808$; Fig. 4b).

The significant quadratic term in polynomial regression (Fig. 4b) of dispersing females on dispersing males indicates that young colonies recruiting workers for the first time release an excess of males, while old colonies contribute relatively more dispersing females. This is consistent with negative frequency dependent selection maintaining an equilibrium population-wide sex ratio to which colonies contribute in a split manner depending on developmental stage. An alternative analysis dividing gallery systems into three productivity classes confirmed that the sex ratio was significantly male biased only in young colonies that produced 1-5 dispersing adults $\left(\chi^{2}=8.00\right.$, d.f. $\left.=1, P<0.005\right)$, consistent with female helpers being disproportionally recruited at this low-productivity stage of gallery development (see Methods and Supplementary Information). Apart from being perennial, this pattern is similar to variation in bivoltine halictid bees, where first-brood sex ratios are male biased because daughters are retained as helpers while second-brood sex ratios are female biased ${ }^{8,29}$.

Genotyping of 559 specimens (workers, pupae, larvae and eggs) from 33 galleries for eight microsatellite loci showed that colony members jointly never had more than four alleles per locus (except for a few cases explainable as $2 \mathrm{bp}$ slipped strand mutations at a single locus), indicative of strict parental monogamy. In the gallery systems where we could also genotype the foundress $(n=9$, Supplementary Tables 4 and 5), all other individuals from the same gallery shared at least one allele at each locus with this female, consistent with all of them being her offspring, and the remaining alleles were consistent with being contributed by a single diploid father. 


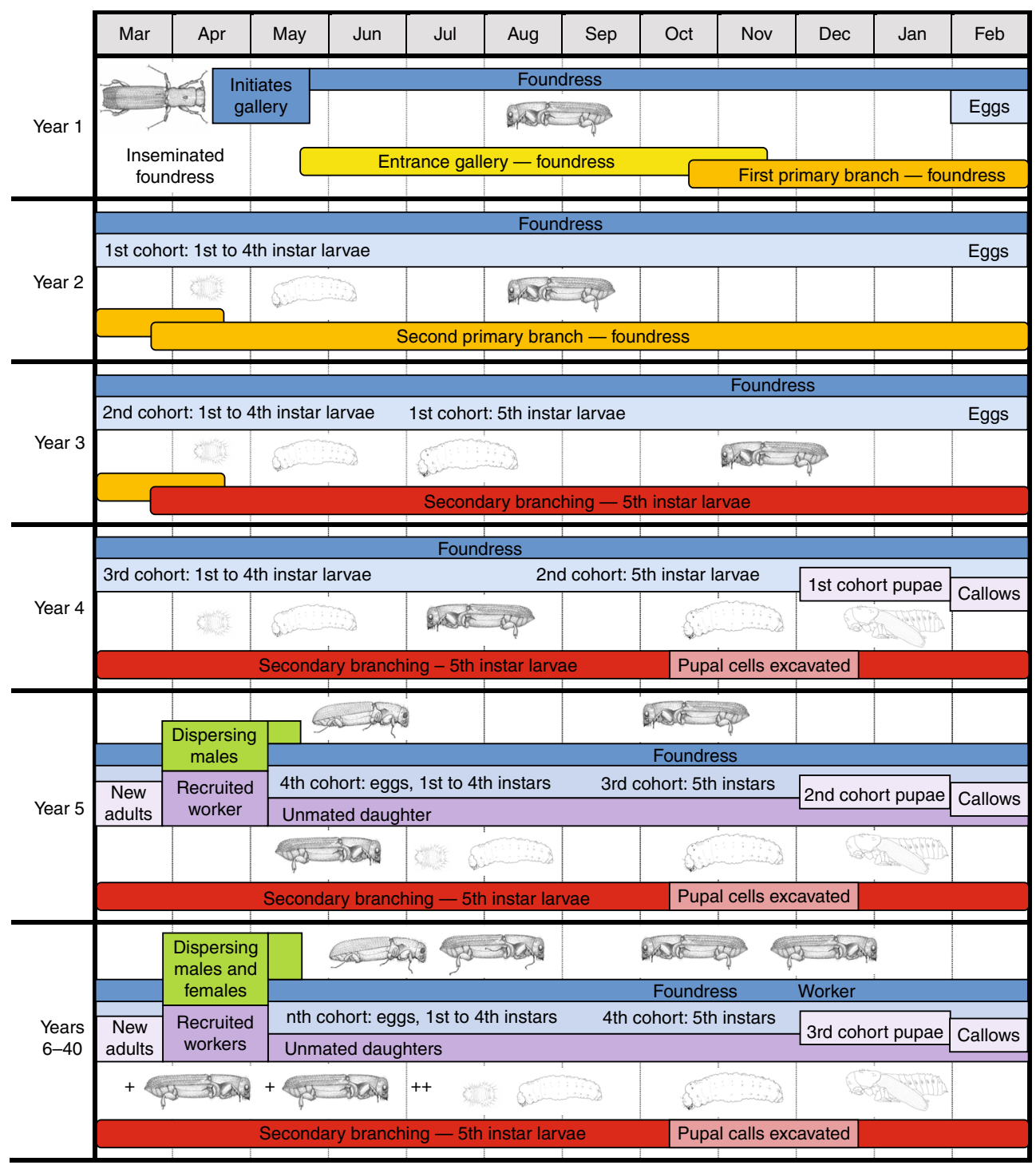

Fig. 2 | Schematic overview of the phenology of gallery founding and colony growth in A. incompertus. Coloured horizontal bars represent year-specific categories of gallery excavation and later branching for the first two years (yellow, entrance gallery; orange, first and second primary branches excavated by the foundress), the next two years (red, secondary branching excavated by the 5th (last) instar larvae), the start of worker recruitment (early year 5) and the subsequent obligately eusocial iteroparous phase (open-ended but defined by the start of worker recruitment and the likely maximum year range of colony survival). The first two cohorts are produced a year apart and consist of only 1-2 and 2-3 offspring, respectively, with the first cohort emerging as adults after four years, and any females among them being recruited as workers (purple box early in year 5 ) and all males dispersing (green box). The second cohort (hatched from eggs laid in year 3 ) emerges a year later with some of the daughters being recruited (purple box early in year 6 ) and other daughters and all males dispersing. Text boxes attached to the bars highlight the presence of different developmental stages and schematic drawings illustrate the habitus of larvae and adults. The bottom of the diagram (years 6 to about 40 ) characterizes the recurrent part of the iteroparous colony life cycle, in which 5th instar larvae of subsequent yearly cohorts continue to excavate new secondary galleries (red), adults of both sexes disperse every year (green), recruitment of workers continues (presumably subject to the number of older workers already present) (purple), and eggs, 1st-4th instar larvae, 5th instar larvae, pupae and newly eclosed callow adults continue to appear in a predictable seasonal pattern that follows the same phenology as in year 5 . The adult foundress is always drawn looking to the left and newly recruited or older workers always look to the right.

These results underline the permanency of full siblingship, because families sampled in year 5 (Fig. 2) will have had a four-year age difference between genotyped eggs and adult workers (Supplementary Table 5), and this age difference will have been $>20$ years for some of the larger genotyped colonies with about 10 workers (Fig. 4a). For 10 genotyped colonies we also had trapping data of dispersers from two subsequent years, which did not yield any new alleles in the second year (Supplementary Information). Full-sibling relatedness thus appears to be maintained, consistent with neither the foundress re-mating later in life nor any helping daughter becoming inseminated after having assumed sterile worker tasks. These data also showed that colony usurpation by a newly mated younger breeder had not occurred (see Supplementary Information).

To complement our pedigree reconstructions, we performed maximum likelihood analysis using COLONY software ${ }^{30}$, which assigned all offspring individuals as full siblings to their nestmates with inclusion probabilities of $\geq 0.98$ in 32 of the 33 galleries. The inclusion probability for the remaining colony was 0.88 , but here the maternal genotype was known and pedigree analysis consistent with a single father (Supplementary Table 5). The average observed relatedness among colony inhabitants was $0.499 \pm 0.006$ (95\% confidence interval, CI) (Supplementary Table 5), consistent 

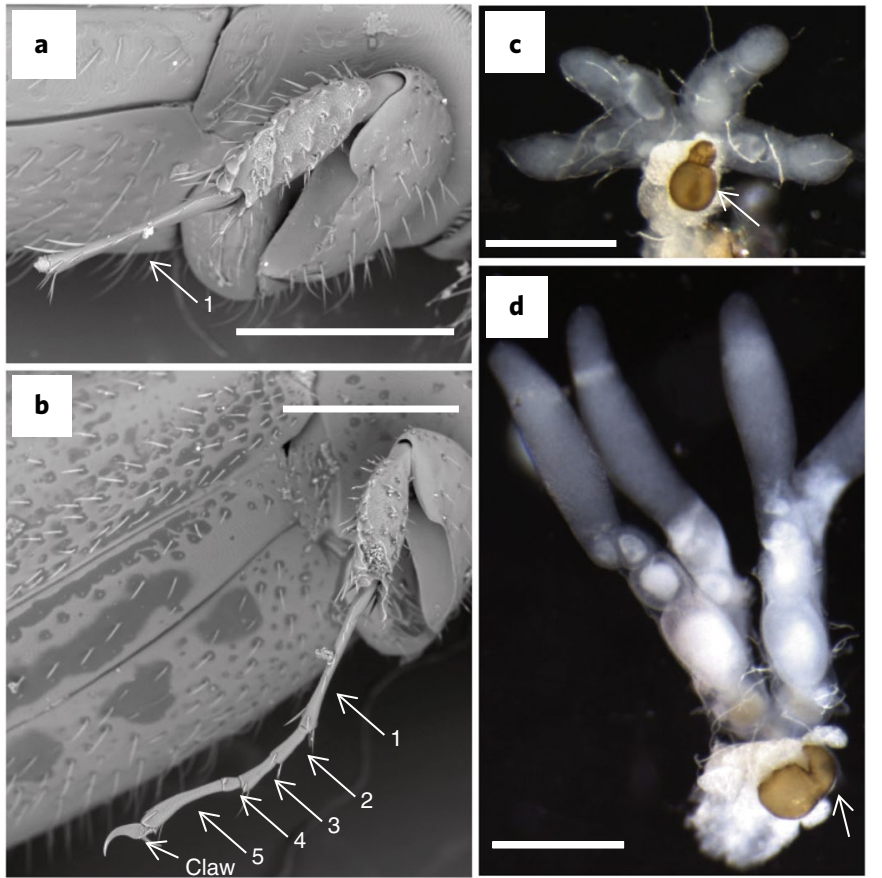

Fig. 3 | Morphological characterization of colony residents and reproductive differences between foundresses and unmated daughter workers. a, Scanning electron microscopy (SEM) micrograph of the midtibia of a resident female, displaying the characteristic loss of the tarsal segments 2-5, leaving only the longest first segment attached (numbered 1); resident females cannot survive outside the gallery system where tarsi and claws are essential for staying attached to the bark. b, SEM micrograph of a dispersing female's mid-tibia displaying the normal (numbered 1-5) tarsal complement and claw. c, The small and inactive ovaries of a representative resident daughter worker with a brown transparent (and thus empty) ovoid spermathecae (arrowed). d, The much larger and active ovaries of a representative reproductive foundress with clearly differentiated oocytes and eggs, and an opaque (filled) spermatheca (arrowed). Scale bars, $500 \mu \mathrm{m}$.

with the theoretically expected value of 0.5 for outbred full siblings $(P=0.762)$. Observed relatedness values were not significantly different from a simulated distribution of relatedness values for 6,000 full-sibling dyads randomly generated from our populationwide allele frequency distributions $(P=0.61)$, which produced an expected nestmate relatedness of $0.497 \pm 0.003$ (95\% CI).

\section{Discussion}

Our results strongly suggest that the extremely long-lived galleries of $A$. incompertus are never inhabited by any beetles other than the single female foundress and her full-sibling offspring. As we discuss below, this inference is consistent with universal tarsal loss of resident females, which precludes mating and new gallery initiation later in life, both for foundresses and for unmated workers. Below, we evaluate additional life-history data that explain the extent to which males and 5th (final) instar larvae contribute labour to social colony life, before proceeding to a more general interpretation of our results.

Mating, tarsal loss and daughter sterility without further specialization. A. incompertus workers were always un-inseminated, consistent with them never mating with brothers inside galleries and with being fully sterile, as both sexes in A. incompertus are diploid so males cannot develop from unfertilized eggs. A. incompertus galleries are known to always be initiated by already inseminated females $^{15}$, and our genetic data demonstrate $100 \%$ parental outbreeding after using a substantial set of markers that reliably discriminated between candidate parents and other first-degree relatives (Supplementary Information). Lifetime (unconditional) unmatedness of workers is a hallmark of obligate eusociality ${ }^{12,13}$. This advanced state of social organization is restricted to the ants, the evolutionarily derived termites, crown-group corbiculate bees and vespine wasps, and is never found in cooperative breeders such as naked mole rats and meerkats or facultatively eusocial invertebrates $^{13}$, including other ambrosia beetles such as $X$. saxeseni, which belongs to the distantly related haplodiploid Xyleborini.

Mating in Platypodinae occurs on a substrate and not in flight ${ }^{23,24}$, making it impossible for females without a full tarsal complement with claws on most legs to either mate and initiate a new gallery or to usurp an existing one ${ }^{31,32}$. For example, in Megaplatypus mutatus (Chapuis), even slight damage to the tarsi prevents reproduction because the male cannot traverse the bark and the females cannot participate in courtship ${ }^{33}$. The universal loss of almost all tarsal segments shortly after committing to a gallery (Supplementary Information) is therefore key to understand the difference between cooperative breeding ambrosia beetles, whose helpers often have later dispersal and/or mating opportunities, and obligate eusociality, where sterile workers have no reproductive potential later in life. Few Platypodines have been studied, but tarsal loss shortly after gallery foundation has been reported in at least seven other Platypodines ${ }^{31,32,34-37}$ and applies to both sexes in proportion to their workload in one better-studied case ${ }^{32}$. Consistent with males having secondarily lost their social roles, tarsal loss is female specific in A. incompertus, but the rate of tarsal loss has remained comparable to non-social sister lineages and is likely to remain proportional to the amount of work done. Hence, foundresses lose their tarsi in a matter of weeks after gallery initiation and workers in a few months after committing to their natal gallery (Supplementary Tables 2 and 3). Tarsal loss in A. incompertus thus happens at a scale never documented in haplodiploid Xyleborini and other cooperatively breeding ambrosia beetles ${ }^{19,25,38}$. Here dispersal is a conditiondependent decision of adult females after evaluating the need for help in their natal gallery and assessing the potential indirect fitness pay-offs emanating from delaying dispersal and becoming helpers ${ }^{39}$.

Females of the relatively well-studied xyleborine species $X$. saxeseni can start their galleries after first having been helpers at the natal nest ${ }^{39}$, suggesting that selection for well-functioning tarsi and claws is maintained throughout life. We hypothesize that lifetime commitment of all females to a single gallery system has relaxed selection for maintaining strong tarsal joints, quite possibly already in the ancestors of $A$. incompertus. Tarsal loss reduced female mobility and restricted mating to the first weeks of adult life, thus reinforcing the maintenance of full-sibling colonies throughout the lifespan of galleries. We expect that tarsal loss in workers is due to wear and tear similar to tarsal loss in foundresses (see Supplementary Information) rather than to active shedding or maternal mutilation, because there is little parent-offspring conflict that needs to be resolved by maternal coercion when relatedness to siblings is identical to relatedness to offspring. Lifetime parental monogamy combined with consistently favourable benefit/cost ratios of reproductive altruism in an existing colony that survived against dismal foundation odds (see below and Supplementary Information) thus provides a credible ultimate explanation for the evolution of lifetime worker unmatedness in A. incompertus.

The intriguing difference between $A$. incompertus and all other obligately eusocial insects is that caste differentiation did not proceed beyond the strict (un)matedness dichotomy. This makes sense when realizing that gallery life with small colonies did not impose selection for enhanced breeder fertility and that ambrosia fungus farming never requires foraging outside the gallery ${ }^{20}$. Constant gallery diameter also implied that body size could neither increase nor 

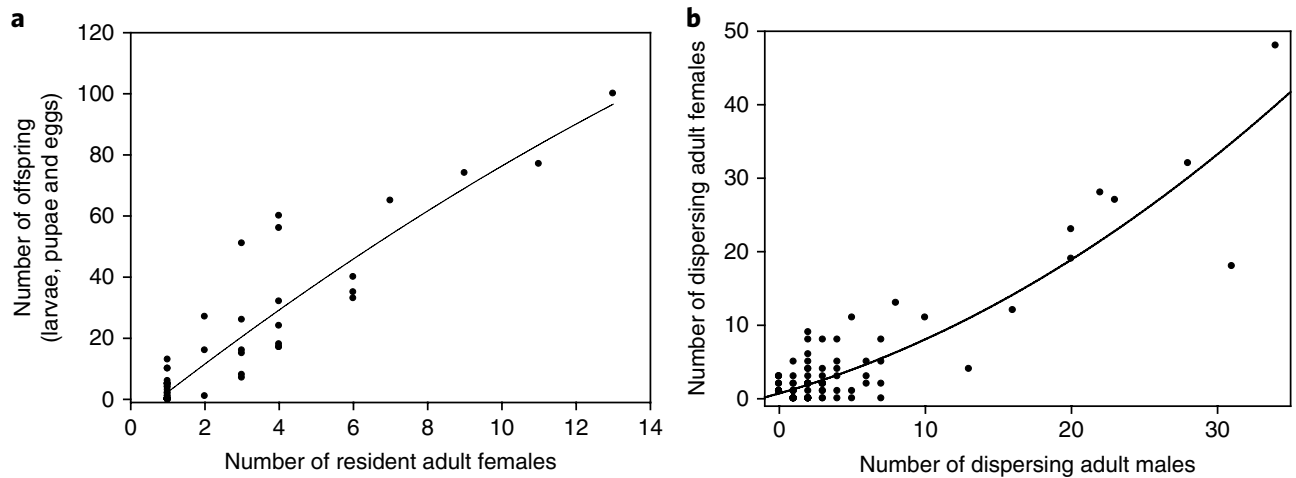

Fig. 4 | Colony productivity and sex allocation. a, The relationship between the number of adult female residents and colony fecundity for 62 active gallery systems for which full census data could be obtained from tree felling and gallery examination. Less than half of these gallery systems $(n=26)$ contained more than one resident female and had six or more immature offspring. Differences between sites $(P=0.418)$ or Eucalyptus tree species $(P=0.771)$ were not significant, and the remaining variation could be described $\left(R^{2}=0.845\right)$ with the polynomial regression equation: offspring number $=9.6($ resident females) -0.12 (resident females) $)^{2}-7.10$, having a significant linear slope $(P<0.0001)$ and a non-significant quadratic slope $(P=0.302)$, the latter indicating that decline in colony fecundity in larger (older) colonies is very minor. $\mathbf{b}$, Yearly colony-level production of dispersing adult females as a function of the number of dispersing adult males for 36 active colonies that were monitored over a five-year period (resulting in 98 sets of micro-cage/dispersal samples). The variation could be described $\left(R^{2}=0.825\right)$ with the polynomial regression equation: females $=0.56$ males $+0.02(\text { males })^{2}+0.73$, having both a significant linear slope $(P<0.0001)$ and a significant quadratic slope $(P<0.003)$, showing that small (young) colonies produce fewer dispersing females and large (old) colonies overproduce dispersing females relative to the overall mean. Some points fell on top of each other so that only 25 of the 26 observations are visible in $\mathbf{a}$ and only 50 of the 98 observations are visible in $\mathbf{b}$.

decrease as the latter would have jeopardized the efficiency of gallery entrance blocking. Platypodid larvae are comparatively independent, move freely around the galleries, feed themselves, and extend galleries when they reach the 5 th instar ${ }^{25}$, similar to the Xyleborini ${ }^{19}$ (see Supplementary Information). This contrasts with the larvae/ nymphs of the obligately eusocial Hymenoptera and termites, which are intensively provisioned and/or nursed by workers ${ }^{1,40}$. This might explain why morphological adaptations for advanced brood care have not evolved in the lifetime unmated workers of $A$. incompertus. This monotypic beetle lineage thus appears to represent an incipient stage of obligately eusocial superorganismality ${ }^{41}$, characterized by the hallmark trait of lifetime unmatedness for all workers, but with very limited additional adaptation due to constraints of fungus farming in self-sufficient galleries of constant diameter. A diagrammatic summary of our reconstruction of the caste-specific phenology of $A$. incompertus females is shown in Fig. 5.

Monogamy first and ecological benefits second. The monogamy hypothesis claims that parental commitment for life was a necessary condition for evolving irreversible reproductive division of labour. The Hamiltonian benefit-cost ratio $(b / c)$ then was the secondary sufficiency condition that allowed some lineages to evolve lifetime unmated castes, while precluding many other monogamous taxa from achieving similar transitions because the $b / c$ ratios of reproductive altruism remained too variable over time. All other studied platypodid ambrosia beetles are monogamous with biparental gallery foundation and brood care but, as far as known, without helpers or a worker caste ${ }^{25,42}$. This indicates that outbred maximal relatedness among siblings was established first and that, as expected ${ }^{3,13}$, efficiency advantages of worker altruism accumulated afterwards, starting with marginal benefits $(b / c>1)$ and ultimately reaching substantial indirect fitness returns (cf. Figure $4 a$ ).

Although few platypodid beetles have been studied in detail, a robust genus-level phylogeny is available which allowed us to use natural history data to shed light on the order in which monogamy and nesting habits evolved (Fig. 6). The genus Austroplatypus evolved ca. $55 \mathrm{Ma}$ in the early Eocene as the most basal branch of the tribe Platipodini ${ }^{16}$. The evolutionarily older Tesserocerini tribe that probably completed its deeper diversification in the Cretaceous appears to be universally characterized by a single male excavating a nest-founding gallery and attracting a female, after which mating takes place at the gallery entrance ${ }^{23}$. The female then continues excavation and the pair cooperates in gallery maintenance, with the female specializing on gallery hygiene and the male on defensive entrance blocking, which also prevents mobile larvae from falling out, and assisting with waste removal and microclimate regulation to secure stable fungus-garden growth ${ }^{23-25}$. The later evolving sister lineages of Austroplatypus within the Platypodini represent most of the extant diversity of the Platypodinae (Fig. 6). Some of the better studied species in these lineages appear to have marginalized maleroles to primarily involve entrance guarding ${ }^{25,42}$ while retaining the use of dead or dying trees for nesting.

The phylogenetic distribution of tunnelling inside live trees (Fig. 6) strongly suggests that the switch from dead, decaying wood to live stems was the decisive sufficiency condition for obligate eusociality in A. incompertus to evolve. This may have happened only once after the necessary condition of lifetime monogamy was broadly established ancestrally, and after male paternal roles had subsequently become reduced to mere entrance defense and finally to survival as stored sperm only. Only a handful of other, evolutionary-derived switches to using live trees have been documented among the approximately 1,400 extant species of platypodid beetles $^{16,25}$ (Fig. 6). Detailed studies of these species would be valuable to elucidate whether convergent forms of reproductive altruism might have evolved in these platypodids and how such derived social systems would correlate with putative losses of social roles in males. It would also be interesting to investigate whether the exceptionally potent chemical defenses of Eucalyptus trees might have been a facilitating factor for prolonged colony life across A. incompertus and the two other live-Eucalyptus-tunnelling species in Australia.

Increased sexual dimorphism and lifetime sperm storage. Sexual dimorphism in A. incompertus appears to reflect obligate eusocial breeding. In other platypodid species, male body size is either the same or very slightly smaller than female body size, but A. incompertus males are always recognizably smaller than females, consistent with males no longer having entrance-guarding or 


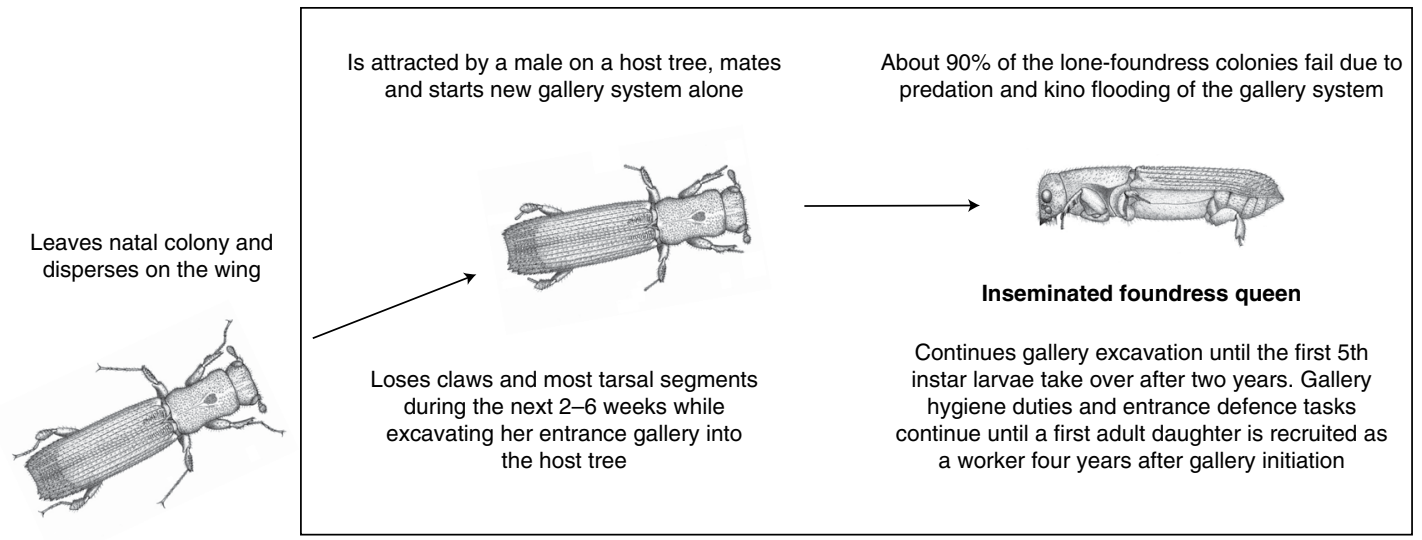

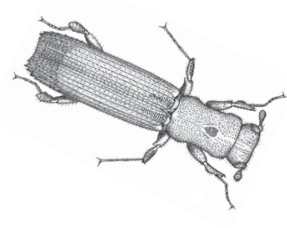

Stays in natal colony and remains unmated

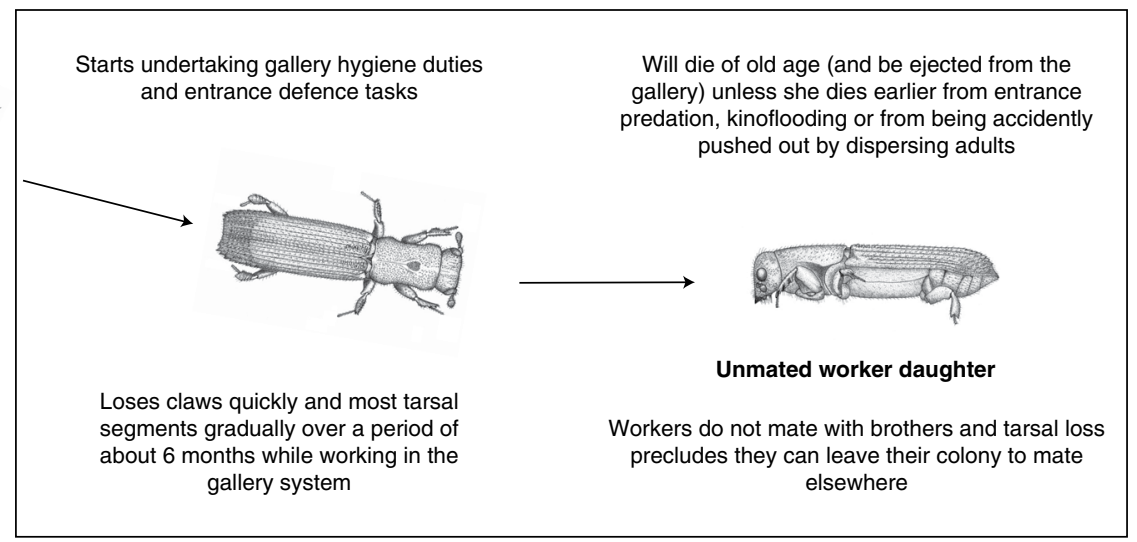

Fig. $\mathbf{5}$ | Summary of the social phenology of $\boldsymbol{A}$. incompertus female castes. Two virgin sisters eclosing in the same colony cohort shortly before the yearly dispersal period irreversibly embark on alternative trajectories as either inseminated foundress queen of a new gallery system elsewhere (top) or as lifetime-unmated worker daughter in the natal colony (bottom). With negligibly few exceptions, dispersal starts in late March, with more males dispersing earlier in this period and female numbers catching up by mid April.

colony-founding behaviours either before or after mating ${ }^{43}$. However, A. incompertus males have remained responsible for locating a suitable host tree where they settle in the bark and probably use a pheromone to attract a female for mating, as in other platypodines $^{44,45}$. This derived male life-history probably explains that A. incompertus males have lost the posterior armature of spines ${ }^{43}$, elytral modifications hypothesized to aid in gallery entrance defe nce $e^{20,31,32,35}$ that males, and to a lesser extent females, of the phylogenetically basal platypodid Notoplatypus elongatus (Lea) have ${ }^{46}$. In contrast, $A$. incompertus females have not only retained their abrupt elytral declivity (sharp downward posterior slope) but these became reinforced with series of central and peripheral spines, making them both suitable for gallery blocking and for hygienic waste shovelling within the gallery. In addition, the mycangia (specialized structures to transport fungus, often present in both male and female Platypodinae) have been lost in A. incompertus males but retained in all females ${ }^{43}$.

The life history traits that our study has uncovered indicate that A. incompertus follows the general rule that parental care in sister lineages without social breeding predicts the sex of an evolutionarily derived permanent worker caste ${ }^{9,10}$. Over evolutionary time, the tunnelling and nursing roles of males disappeared (now only found in extant sister lineages), so it was to be expected that $A$. incompertus males would not evolve permanent worker functions, provided that females could evolve the male-like morphological modifications that enabled them to be efficient entrance guards ${ }^{43}$. Strictly monogamous biparental care thus appears to have been replaced by lifetime sperm storage and exclusive maternal care, in contrast to the diploid termites that retained the biparental colony founding habits of their cockroach ancestors when evolving social colonies, both initially when becoming wood-dwellers nesting inside logs, and later when evolving true workers and superorganismal colonies with central place foraging ${ }^{12,13,41}$. Our data on $A$. incompertus confirm that the evolution of lifetime sperm storage is not just a hymenopteran idiosyncrasy ${ }^{47,48}$, but a pre-adaptation facilitating the evolution of lifetime sterile castes independent of ploidy because it helps securing lifetime monogamy ${ }^{3,13}$.

General implications of a lifetime sterile caste in a long-lived ambrosia beetle. Two final implications of our study deserve to be made explicit. First, that the evolution of phenotypically plastic helpers in cooperatively breeding lineages has been proposed to be driven by either the need for 'fortress defence' or 'life insurance" ${ }^{1}$, an argument that is also valid for the haplodiploid Xyleborini ambrosia beetles ${ }^{19}$. However, these mechanisms do not apply in A. incompertus because workers are not present during the first four years after colony founding (Fig. 2) when gallery systems are most likely to fail (Supplementary Information). This is because lone foundresses are vulnerable to predation in their entrance gallery, and can perish when their gallery entrance is flooded by Eucalyptus kino ${ }^{26}$. Chemical host tree defenses and predation risk continue throughout the lifespan of the colony, but after the first workers are recruited the foundress is unlikely to be exposed close to the gallery entrance and the risk of being overwhelmed by kino is much reduced. This suggests that especially the first workers obtain substantial indirect fitness benefits by staying rather than dispersing and pursuing the perilous life of a lone foundress (Fig. 5).

The second general implication arises as a consequence of improved colony survival. Once foundresses have survived long enough to produce their first dispersing sons and recruit their first 


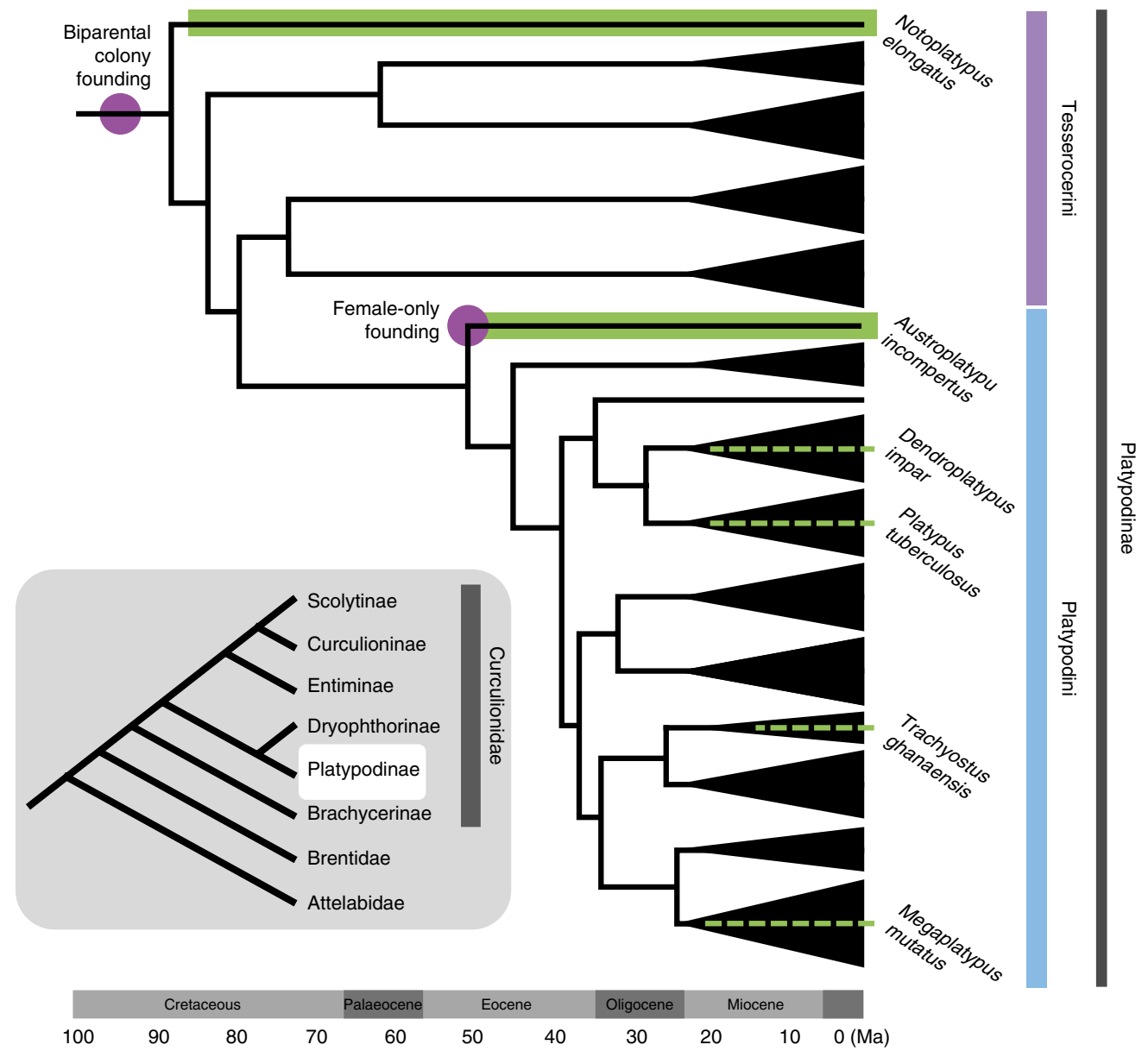

Fig. 6 | Phylogenetic placement of $A$. incompertus and other live-tree-tunnelling platypodid beetle species. A stylized phylogeny for the diploid subfamily Platypodinae ${ }^{16}$ showing the evolutionary position of $A$. incompertus relative to other Platypodinae. Austroplatypus is most likely to have evolved in the early Eocene around $55 \mathrm{Myr}$ ago $(\mathrm{Ma})\left(95 \% \mathrm{Cl}\right.$ of posterior value $\left.45-64 \mathrm{Ma}^{16}\right)$ and is monotypic, that is, has only a single known extant species $A$. incompertus. Its lifestyle of tunnelling in live hardwood Eucalyptus trees is likely to be ancestral, as the genus Eucalyptus is generally acknowledged to have evolved approximately $52 \mathrm{Ma}$ (also in the early Eocene) ${ }^{59}$. Most diversification in Platypodinae happened in the sister branches of $A$. incompertus within the Platypodini tribe, which retained ancestral biparental gallery founding in dead wood (black branches). Several derived and isolated other transitions to live hardwood tunnelling are known, including one in the Neotropics (Megaplatypus mutatus (Chapuis)), one in the Afrotropics (Trachyostus ghanaensis Schedl), one in Indo-Malaya (Dendroplatypus impar (Schedl)) and two in distantly related Australian lineages (Platypus tuberculosus Strohmeyer and Notoplatypus elongatus Lea ${ }^{16,25}$. All six species lineages that tunnel in live trees are highlighted in green when sequence data were available or with dashed green lines when phylogenetic positions could only be approximately inferred. The inset schematic tree depicts the well-supported evolutionary relationships across the weevil (Curculionidae) subfamilies ${ }^{17}$. Ploidy varies across the branches of the Curculionidae, but has rarely been directly confirmed. The Scolytinae include both haplodiploid and diploid taxa, and the better-known examples of cooperative breeding are all from the haplodiploid tribe Xyleborini within the subfamily Scolytinae $38,39,60$.

worker daughters, they have potential future life expectancies of 10,20 or even 30 or more years ${ }^{15,26}$. This huge contrast between mortality before and after reaching the age of first reproduction selects for extreme longevity ${ }^{49,50}$ and our data suggest that selection for long lifespan may have been extended to the unmated workers of $A$. incompertus. This offers an interesting contrast with the (obligately eusocial) superorganismal central-placeforaging Hymenoptera and termites ${ }^{12}$, where workers are much shorter-lived than their well-protected mother queens (and kings in termites) who may have similar lifespans as A. incompertus foundresses ${ }^{48}$. Although $A$. incompertus workers are unable, and have no reason, to leave the gallery to forage, their entrance guarding duties will impose higher extrinsic mortality risks than those experienced by their mothers. Life history theory ${ }^{51}$ would thus predict that sterile workers have shorter lifespans than breeders, but that their rate of ageing may also be very low compared to other ambrosia beetles.

\section{Methods}

Sampling. Several sampling regimes were employed at three locations in New South Wales, Australia (Supplementary Table 1): Olney State Forest $\left(33^{\circ} 5^{\prime} 51.42^{\prime \prime} \mathrm{S}, 151^{\circ} 20^{\prime} 59.94^{\prime \prime} \mathrm{E}\right)$, Ourimbah State Forest $\left(33^{\circ} 17^{\prime} 38.11^{\prime \prime} \mathrm{S}\right.$, $\left.151^{\circ} 20^{\prime} 30.38^{\prime \prime} \mathrm{E}\right)$ and Cumberland State Forest ( $33^{\circ} 44^{\prime} 42.37^{\prime \prime} \mathrm{S}, 151^{\circ} 2^{\prime} 21.31^{\prime \prime} \mathrm{E}$; Fig. 1a). Whole-log processing of Eucalyptus pilularis and E. agglomerata trees enabled the investigation of gallery system phenology ( $n=230$ galleries) and colony demography (collecting/counting all adults, larvae/pupae and eggs from 62 active gallery systems) (Supplementary Table 1). All inhabitants from a subset of gallery systems collected in 2010 ( $n=16$, adult beetles, larvae and eggs) were also collected for genetic marker analyses. In addition to whole-log processing, brass gauze micro-cages were placed over the entrances of gallery systems to trap beetles during their annual dispersal period (late March to early May) when males fly from their natal galleries to locate a host tree, settle in the bark and attract females to mate (Fig. 2). These collections allowed us to estimate sex ratios of dispersing adult offspring produced by 64 colonies. Each of these gallery systems was tagged to enable its tracking over subsequent years. Once dispersal of beetles commenced, the micro-cages and gallery entrances were inspected at varying time intervals (dependent on specific objectives in early studies; see the Supplementary Information) to collect trapped beetles whose typical behaviour 
was noted before they were sorted according to sex. One individual emerging from each of the 96 caged gallery systems in Olney State Forest was preserved in $90 \%$ ethanol for obtaining unbiased reference population allele frequencies for microsatellite marker loci. For a subset of 20 gallery systems all adults emerging over two consecutive years were collected for genetic analyses of possible changes in family composition over time. In this instance, 10 larger/older gallery systems (characterized by a protruding kino tube with finely granulated frass; Fig. 1c, third and fourth photographs) and 10 smaller/younger gallery systems (characterized by a shorter red kino tube with frass of wood slivers/granules; Fig. 1c, first and second photographs) were sampled (Supplementary Table 1; see also Supplementary Information). This implies that a variety of gallery age classes was represented in our total sample of colonies used for our genetic analyses.

Gallery phenology and seasonal activity. Gallery systems (E. pilularis $n=58$ or E. agglomerata $n=172$ ) of various ages were examined to investigate the typical sequence of gallery development. For each gallery system, the location, status (inactive vs active) and developmental stage (detailed below) were assessed with reference to previous general sources of information pertaining to the beetles' life history ${ }^{15,26}$. Monitoring and sampling of galleries occurred over a series of years at different times of the year outside of the dispersal period of adult beetles (late March to early May). This allowed us to reconstruct the entire life cycle of $A$. incompertus, from gallery initiation, via recruitment of the first workers after four years, and throughout the long iteroparous final phase, including the seasonal phenology events of brood development (Figs. 1c and 2; Supplementary Information; Supplementary Tables 1-3).

The observed horizontal gallery systems showed a number of common features and a consistent sequence of development which included three distinct phases (Supplementary Information). (1) Entrance stage: the initial gallery excavated by the lone foundress leads straight into the tree (roughly perpendicular to the tree surface) without branching and stops just short of the pith. (2) Primary branching stage: once the entrance gallery is near the pith, it radially branches off to the left or right following a growth ring (Fig. 1c, first drawing). After this branch has been completed another is excavated in opposite direction, starting at the point where the previous primary branch diverged from the entrance gallery. (3) Secondary branching stage: after completion of the primary branches, secondary branches and pupal cells (short vertical galleries with concave ends in which larvae pupate) are excavated by 5 th instar larvae (Supplementary Information). Once this stage has been reached, the gallery 'bauplan' is essentially complete (Fig. 1c, second drawing). From now on the gallery system will continue to develop in complexity for as long as the colony lives, via additional galleries being excavated by 5 th instar larvae away from the pith into the heartwood (Fig. 1c, third drawing), so the gallery system merely increases in overall diameter and overall gallery length (Fig. 1c, fourth drawing) until the colony ultimately fails after up to about 40 years $^{15,26}$

Colony demography and sex ratio. For 62 active gallery systems collected via destructive sampling, the stage of gallery development was recorded as described above (Fig. 1c). This included noting the sex and presence/absence of claws of each adult, and the number of eggs and larvae-the latter sorted into instar cohorts according to previously documented morphological characteristics ${ }^{43}$. The ovaries of all resident females from 16 of these gallery systems were examined by dissection in saline solution at $40 \times$ magnification, and their spermathecae removed and ruptured onto a slide to check for the presence of sperm by viewing with a compound microscope.

To investigate the sex ratios of adults emerging from active gallery systems, micro-cages were placed on the entrances of 64 active $A$. incompertus colonies, which allowed 829 emerging beetles to be collected from 36 of these colonies over a five-year period giving a total of 98 sampling events (Supplementary Table 1). Beetles disperse from their colonies during late March to early May (Supplementary Information) so the micro-cages were inspected monthly from July to February and weekly from March to April until beetle dispersal commenced. Micro-cages were then inspected daily (78\%) or every second day (14\%) (generally until June) and the collected beetles were counted and sorted according to $\operatorname{sex}^{43}$ (the remaining $8 \%$ of cases involved longer trap inspection intervals ( 3 days on 5 occasions; 4 days on 3 occasions and 6 days on a single occasion). For data analysis, these gallery systems were divided into three productivity classes based on numbers of dispersing adults in each year (using total annual productivity as a proxy of colony age, but corresponding with kino tube age estimations; Fig. 1c), giving three categories: small ( $1-5$ dispersers, $n=64)$, medium (6-15 dispersers, $n=22)$, and large (16-82 dispersers, $n=12$ ). We used polynomial regression to analyse sex ratio variation across the entire data set $(n=98)$.

The extent and pattern of tarsal loss. Tarsi and claws are essential for platypodine beetle mobility outside the gallery system so females without tarsi can neither leave their colony on foot nor disperse to other trees on the wing because they are unable to cling to the bark when landing on trees ${ }^{31,32,34}$. We investigated the extent and nature of tarsal loss in A. incompertus beetles using: 1 . Tree felling and gallery dissection in the months of January, February, June, August, October and November, all of which are outside the late March to early May dispersal period;
2. Monitoring gallery initiation occurring in late May; 3 . Inspecting micro-cages which collected dispersing offspring from late March to early May and some nondispersing females from early March to late June, and 4. Opportunistic collection of non-dispersing females from kino tubes (Supplementary Table 1). Frequency distributions of the presence or absence of claws and tarsal segments at specific collection dates were examined (Supplementary Table 2 and 3), which allowed us to evaluate the timing of tarsal loss and whether tarsal loss implied clean breaks between segments (almost always) or possible cases that could be consistent with segments having been actively broken/torn off (Supplementary Information).

Microsatellite genotyping. Total genomic DNA was extracted from the heads of adults or approximately half of the body mass of 3rd, 4th or 5th instar larva using an ammonium acetate precipitation protocol. A 10\% Chelex-solution (SigmaAldrich) was used to extract DNA from eggs and 1st or 2 nd instar larva $(100 \mu$ of $10 \%$ Chelex and $10 \mu \mathrm{l}$ of $10 \mu \mathrm{g}$ proteinase K, Sigma-Aldrich, $10 \mathrm{hr}$ at $56^{\circ} \mathrm{C}$, $100^{\circ} \mathrm{C}$ for $15 \mathrm{~min}$, then $10 \mathrm{~min}$ at $21,000 \mathrm{~g}$, after which supernatant was collected). Individuals were genotyped for eight loci; $A i 1^{52}$, Ai3, Ai5, Ai6, Ai9, Ai12, Ai19 and $A i 2 O^{53}$. Welded fluorochromes (Applied Biosystems) were incorporated into the forward primer for PCR and later electrophoresis with an ABI 3130 Genetic Analyser (Applied Biosystems). Allele sizes were estimated against an internal size standard LIZ using Peak Scanner Software v1.0 (Applied Biosystems). More than $15 \%$ of samples were re-analysed (different ones for each locus) to ensure consistency and repeatability of allelic scores when first round banding patterns were ambiguous. Primer details, loci properties, PCR conditions and allele sizing protocols have been published previously ${ }^{52,53}$.

Summary statistics (Supplementary Table 4) include the number of alleles per locus, measures of observed and expected heterozygosity, and tests for deviation from Hardy-Weinberg Equilibrium, based on the genotypes from our reference population (single individuals from 96 colonies at Olney State Forest) and computed using CERVUSv3.0.3 $3^{54}$. Originally, nine loci were genotyped, but one locus showed a significant deficiency of heterozygotes compared with expected Hardy-Weinberg equilibrium, most likely due to null alleles, and was discarded from further analyses. None of the remaining eight loci deviated significantly from Hardy-Weinberg equilibrium (examined using micro-checker ${ }^{55}$ v.2.2.3 and CERVUS). Combined, these eight loci provided considerable power for assigning pedigree relationships (Supplementary Table 4) with a mean polymorphic information content of 0.69 and a combined CERVUS probability of overlooking a putative second insemination of 0.0008 , implying that the probability of detecting multiple paternity (if it existed) with this marker set was high.

Colony genetic structure. Pedigree relationships among the genotyped inhabitants $(n=590)$ of 36 colonies were initially investigated by visual inspection of genotypic arrays. Because both sexes in $A$. incompertus are diploid ${ }^{52}$, a maximum of four alleles per locus is expected among offspring when a breeding female is inseminated by a single male. Visual appraisal of pedigree genotypes where the maternal genotype was known $(n=10)$ also allowed us to reconstruct the other parental genotypes which always yielded a single diploid mother and father. Putative genetic inconsistency with a single mother and father $(>4$ alleles at a locus per colony, or a combination of alleles inconsistent with the two inferred parental genotypes) was identified for only 7 out of 580 individuals, and always occurred at only a single locus per individual, suggestive of a genotyping error or mutation. In three of these cases the mismatched locus was homozygous, indicative of a low frequency of null alleles (allelic dropouts) in the population. In three other cases, the mismatched individual also concerned a single locus and an allele differing by just two base pairs from the expected common parental allele, consistent with an occasional slipped strand mutation. Finally, there was one egg that appeared to be homozygous for all eight loci with all alleles being maternal, suggesting it was unfertilized but had undergone some cell divisions (and thus amplified). These seven individuals were removed from subsequent analyses.

Within-colony pedigree relationships were further investigated by implementing a maximum likelihood approach in COLONY ${ }^{30}$ to assign full-sibling relationships among individuals based on their multilocus genotypes (and the associated probability of each assignment). As before, the population-wide allele frequencies (calculated using GenALEx ${ }^{56}$ ), obtained from a single individual per colony $(n=96)$, were used as background reference in this analysis. No a priori assumptions of relationships were made, that is, no kin structure was entered into the analyses up front. The pedigree reconstructions always yielded simple family structures consistent with just two monogamous parents. Full siblingship obtained via COLONY ${ }^{30}$ was further verified by estimating relatedness coefficients. For this approach, individuals were omitted if there were missing data for four or more loci, or if they were members of a colony for which only four or fewer individuals were genotyped. These stringent criteria excluded three colonies, including one small gallery for which emerging adults had been sampled over two years, and two galleries which had been sampled via whole-log processing (including one of the ten that had a putative foundress collected; hence $n=33$ in Supplementary Table 5). All remaining putative foundresses $(n=9)$ were also excluded (as not being offspring), and relatedness ${ }^{57}$ among putative sibling colony members was estimated in COANCESTRY (v1.0.1.5) ${ }^{58}$ for the remaining 550 individuals (from 33 colonies; Supplementary Table 5). We used the same program to simulate the mean and 
colony-level variation in relatedness estimated from 6,000 pairs of first-degree relatives randomly generated from the reference population allele frequencies and compared the outcome with our observed relatedness distribution using a randomization test based on the difference in means between the observed and simulated data sets after 1,000 permutations.

Reporting Summary. Further information on experimental design is available in the Nature Research Reporting Summary linked to this article.

Data availability. The data that support the findings of this study are available from the corresponding author upon reasonable request. The main background data are provided via Supplementary Tables 1-5, among which Supplementary Tables 1-3 summarize all information relevant for the present study from the unpublished PhD thesis of D.S.K. (2001, University of Sydney).

Received: 5 September 2016; Accepted: 13 March 2018; Published online: 23 April 2018

\section{References}

1. Queller, D. C. \& Strassmann, J. E. Kin selection and social insects. Bioscience 48, 165-175(1998).

2. Crespi, B. J. \& Yanega, D. The definition of eusociality. Behav. Ecol. 6, 109-115 (1995).

3. Boomsma, J. J. Kin selection versus sexual selection: why the ends do not meet. Curr. Biol. 17, R673-R683 (2007)

4. Marshall, J. A. R. Social Evolution and Inclusive Fitness Theory: An Introduction (Princeton Univ. Press, Princeton, 2015).

5. Gardner, A., Alpedrinha, J. \& West, S. A. Haplodiploidy and the evolution of eusociality: split sex ratios. Am. Nat. 179, 240-256 (2012).

6. Alpedrinha, J., Gardner, A. \& West, S. A. Haplodiploidy and the evolution of eusociality: worker reproduction. Am. Nat. 184, 303-317 (2014).

7. Fromhage, L. \& Kokko, H. Monogamy and haplodiploidy act in synergy to promote the evolution of eusociality. Nat. Commun. 2, 397 (2011).

8. Quiñones, A. E. \& Pen, I. A unified model of hymenopteran preadaptations that trigger the evolutionary transition to eusociality. Nat. Commun. 8, 15920 (2017).

9. Davies, N. G., Ross, L. \& Gardner, A. The ecology of sex explains patterns of helping in arthropod societies. Ecol. Lett. 19, 862-872 (2016).

10. Ross, L., Gardner, A., Hardy, N. \& West, S. A. Ecology, not the genetics of sex determination, determines who helps in eusocial populations. Curr. Biol. 23 2383-2387 (2013).

11. Hughes, W. O. H., Oldroyd, B. P., Beekman, M. \& Ratnieks, F. L. W. Ancestral monogamy shows kin selection is key to the evolution of eusociality. Science 320, 1213-1216 (2008)

12. Boomsma, J. J. Lifetime monogamy and the evolution of eusociality. Phil. Trans. R. Soc. B 364, 3191-3207 (2009).

13. Boomsma, J. J. Beyond promiscuity: mate-choice commitments in social breeding. Phil. Trans. R. Soc. B 368, 20120050 (2013).

14. Beekman, M., Peeters, C. \& O’Riain, M. J. Developmental divergence: a neglected variable in understanding the evolution of reproductive skew in social animals. Behav. Ecol. 17, 622-627 (2006).

15. Kent, D. \& Simpson, J. Eusociality in the beetle Austroplatypus incompertus (Coleoptera: Curculionidae). Naturwissenschaften 79, 86-87 (1992).

16. Jordal, B. H. Molecular phylogeny and biogeography of the weevil subfamily Platypodinae reveals evolutionarily conserved range patterns. Mol. Phylogen. Evol. 92, 294-307 (2015).

17. Jordal, B. H., Smith, S. M. \& Cognato, A. I. Classification of weevils as a data-driven science: leaving opinion behind. ZooKeys 439, 1-18 (2014).

18. Gillett, C. P. Bulk de novo mitogenome assembly from pooled total DNA elucidates the phylogeny of weevils (Coleoptera: Curculionoidea). Mol. Biol. Evol. 31, 2223-2237 (2014).

19. Biedermann, P. H. W. \& Taborsky, M. Larval helpers and age polyethism in ambrosia beetles. Proc. Natl Acad. Sci. 108, 17064-17069 (2011).

20. Kirkendall, L. R., Biedermann, P. H. W. \& Jordal, B. H. in Bark Beetles: Biology and Ecology of Native and Invasive Species (eds Vega, F. E. \& Hofstetter, R. W.) 85-156 (Academic, Boston, 2015).

21. Biedermann, P. H., Klepzig, K. D., Taborsky, M. \& Six, D. L. Abundance and dynamics of filamentous fungi in the complex ambrosia gardens of the primitively eusocial beetle Xyleborinus saxesenii Ratzeburg (Coleoptera: Curculionidae, Scolytinae). FEMS Microbiol. Ecol. 83, 711-723 (2013).

22. Ulyshen, M. D. Wood decomposition as influenced by invertebrates. Biol. Rev. 91, 1-17 (2014).

23. Jover, H. Note préliminaire sur la biologie des Platypodidae de Basse-Cote d'lvoire. Rev. Pathol. Vég. Entomol. Agric. Fr. 31, 73-81 (1952).

24. Kirkendall, L. R. The evolution of mating systems in bark and ambrosia beetles (Coleoptera: Scolytidae and Platypodidae). Zool. J. Linn. Soc. 77, 293-352 (1983).
25. Kirkendall, L. R., Kent, D. S. \& Raffa, K. F. in The Evolution of Social Behavior in Insects and Arachnids (eds Choe, J. C. \& Crespi, B. J.) Ch. 9, 181-215 (Press Syndicate Univ. Cambridge, Cambridge, 1997).

26. Harris, J., Campbell, K. \& Wright, G. M. Ecological studies on the horizontal borer Austroplatypus incompertus (Schedl) (Coleoptera: Platypodidae). J. Entomol. Soc. Aust. (NSW) 9, 11-21 (1976).

27. Kent, D. Distribution and host plant records of Austroplatypus incompertus (Schedl)(Coleoptera: Curculionidae: Platypodinae). Aust. Entomol. 35, 1-6 (2008).

28. Trivers, R. L. \& Hare, H. Haplodiploidy and the evolution of the social insects. Science 191, 249-263 (1976).

29. Seger, J. Partial bivoltinism may cause alternating sex-ratio biases that favour eusociality. Nature 301, 59-62 (1983).

30. Jones, O. R. \& Wang, J. COLONY: a program for parentage and sibship inference from multilocus genotype data. Mol. Ecol. Res. 10, 551-555 (2010).

31. Browne, F. G. in Fourth Report of the West African Timber Borer Research Unit 15-30 (Eyre and Spottiswoode Ltd, Chiswick Press, London, 1961).

32. Roberts, H. in Fourth Report of the West African Timber Borer Research Unit 31-38 (Eyre and Spottiswoode Ltd, Chiswick Press, London, 1961).

33. Liguori, P. G., Zerba, E. \& Audino, P. G. New trap for emergent Megaplatypus mutatus. Can. Entomol. 139, 894-896 (2007).

34. Beeson, C. F. C. The life history of Diapus furtivus, Sampson. Indian For. Rec. 6, 1-29 (1917).

35. Milligan, R. H. Platypus apicalis White, Platypus caviceps Broun, Platypus gracilis Broun (Coleoptera: Platypodidae): The Native Pinhole Borers (Forest and Timber Insects of New Zealand No. 37, Forest Research Institute of New Zealand, 1979).

36. Browne, F. G. The Biology of Malayan Scolytidae and Platypodidae (Government Press, Kuala Lumpur, 1961).

37. Baker, J. M. Investigations on the oak pinhole borer, Platypus cylindricus Fab. In Record of the 1956 Annual Convention of the British Wood Preserving Association 92-111 (British Wood Preserving Association, 1956).

38. Biedermann, P. H., Klepzig, K. D. \& Taborsky, M. Costs of delayed dispersal and alloparental care in the fungus-cultivating ambrosia beetle Xyleborus affinis Eichhoff (Scolytinae: Curculionidae). Behav. Ecol. Sociobiol. 65, 1753-1761 (2011).

39. Peer, K. \& Taborsky, M. Delayed dispersal as a potential route to cooperative breeding in ambrosia beetles. Behav. Ecol. Sociobiol. 61, 729-739 (2007).

40. Korb, J., Buschmann, M., Schafberg, S., Liebig, J. \& Bagneres, A. G. Brood care and social evolution in termites. Proc. Biol. Sci. R. Soc. 279, 2662-2671 (2012).

41. Boomsma, J. J. \& Gawne, R. Superorganismality and caste differentiation as points of no return: how the major evolutionary transitions were lost in translation. Biol. Rev. Camb. Philos. Soc. 93, 28-54 (2018).

42. Tarno, H., Qi, H., Yamasaki, M., Kobayashi, M. \& Futai, K. The behavioural role of males of Platypus quercivorus Murayama in their subsocial colonies. AGRIVITA J. Agricult. Sci. 38, 47-54 (2016).

43. Kent, D. S. The external morphology of Austroplatypus incompertus (Schedl) (Coleoptera, Curculionidae, Platypodinae). ZooKeys 56, 121-140 (2010).

44. Milligan, R. H. \& Ytsma, G. Pheromone dissemination by male Platypus apicalis White and P. gracilis Broun (Col., Platypodidae). J. Appl. Entomol. 106, 113-118 (1988)

45. Audino, P. G., Villaverde, R., Alfaro, R. \& Zerba, E. Identification of volatile emissions from Platypus mutatus (=sulcatus)(Coleoptera: Platypodidae) and their behavioral activity. J. Econ. Entomol. 98, 1506-1509 (2005).

46. Lea, A. On Australian and Tasmanian Coleoptera, with descriptions of new species. Part I. Proc. R. Soc. Vic. 22, 113-152 (1909).

47. Boomsma, J. J., Baer, B. \& Heinze, J. The evolution of male traits in social insects. Annu. Rev. Entomol. 50, 395-420 (2005).

48. Keller, L. \& Genoud, M. Extraordinary lifespans in ants: a test of evolutionary theories of ageing. Nature 389, 958-960 (1997).

49. Charnov, E. L. \& Schaffer, W. M. Life-history consequences of natural selection: Cole's result revisited. Am. Nat. 107, 791-793 (1973).

50. Kramer, B. H. \& Schaible, R. Life span evolution in eusocial workers-a theoretical approach to understanding the effects of extrinsic mortality in a hierarchical system. PLoS ONE 8, e61813 (2013).

51. Kirkwood, T. B. L. Evolution of ageing. Nature 270, 301-304 (1977).

52. Smith, S. M., Beattie, A. J., Kent, D. S. \& Stow, A. J. Ploidy of the eusocial beetle Austroplatypus incompertus (Schedl) (Coleoptera, Curculionidae) and implications for the evolution of eusociality. Insect Soc. 56, 285-288 (2009).

53. Smith, S., Joss, T. \& Stow, A. Successful development of microsatellite markers in a challenging species: the horizontal borer Austroplatypus incompertus (Coleoptera: Curculionidae). Bull. Ėntomol. Res. 101, 551-555 (2011).

54. Kalinowski, S. T., Taper, M. L. \& Marshall, T. C. Revising how the computer program CERVUS accommodates genotyping error increases success in paternity assignment. Mol. Ecol. 16, 1099-1106 (2007).

55. Van Oosterhout, C., Hutchinson, W. F., Wills, D. P. \& Shipley, P. MICROCHECKER: software for identifying and correcting genotyping errors in microsatellite data. Mol. Ecol. Notes 4, 535-538 (2004). 
56. Peakall, R. \& Smouse, P. E. GenAlEx 6.5: genetic analysis in Excel. Population genetic software for teaching and research-an update. Bioinformatics 28, 2537-2539 (2012).

57. Queller, D. C. \& Goodnight, K. F. Estimating relatedness using genetic markers. Evolution 43, 258-275 (1989).

58. Wang, J. COANCESTRY: a program for simulating, estimating and analysing relatedness and inbreeding coefficients. Mol. Ecol. Resour. 11, 141-145 (2011).

59. Macphail, M. \& Thornhill, A. H. How old are the eucalypts? A review of the microfossil and phylogenetic evidence. Austr. J. Botany 64, 579-599 (2016).

60. Jordal, B. H., Sequeira, A. S. \& Cognato, A. I. The age and phylogeny of wood boring weevils and the origin of subsociality. Mol. Phylogenetics Evol. 59, 708-724 (2011).

\section{Acknowledgements}

Parts of this work were funded by grants to S.M.S. from the Australian Entomological Society, the Genetics Society of Australasia and a Maxwell Ralph Jacobs Award (Institute of Foresters of Australia). S.M.S. was also supported by a grant with M. Riegler (Western Sydney University) from the Australian Government's Australian Biological Resources Study (ABRS) National Taxonomy Research Grant Program (NTRGP). J.J.B. was supported by a grant from the Danish National Research Foundation (DNRF57) and a Newton Abraham Visiting Professorship at Oxford, UK. R. Wurher and S. Hager (Western Sydney University) facilitated the scanning electron microscopy. We thank A. Britton and C. Slade, Forestry Corporation NSW, for tree processing and permissions to work in State Forests (Permit XX43239), A. Beattie, C. Turnbull, S. Dennison,
M. Ciret, M. Smith and C. Angus for assistance in the field or laboratory and J. O'Hanlon for assistance with graphics in Fig. 6.

\section{Author contributions}

S.M.S. conceived, designed and implemented the genetic investigations including the required sampling and undertook the statistical analyses with input from A.J.S. and J.J.B. D.S.K. conceived and designed the whole-tree and micro-cage/dispersal sampling protocols, contributed the gallery phenology analysis, undertook the tarsal loss investigations, and conceived and designed Figs. 2 and 5. S.M.S., D.S.K., J.J.B. and A.J.S. analysed the data. S.M.S. and J.J.B. wrote the paper with substantial contributions from D.S.K. and A.J.S.

\section{Competing interests}

The authors declare no competing interests.

\section{Additional information}

Supplementary information is available for this paper at https://doi.org/10.1038/ s41559-018-0533-3.

Reprints and permissions information is available at www.nature.com/reprints. Correspondence and requests for materials should be addressed to S.M.S. or J.J.B.

Publisher's note: Springer Nature remains neutral with regard to jurisdictional claims in published maps and institutional affiliations. 


\section{natureresearch}

Corresponding author(s): Shannon Smith, Jacobus Boomsma

Initial submission $\square$ Revised version $\$ Final submission

\section{Life Sciences Reporting Summary}

Nature Research wishes to improve the reproducibility of the work that we publish. This form is intended for publication with all accepted life science papers and provides structure for consistency and transparency in reporting. Every life science submission will use this form; some list items might not apply to an individual manuscript, but all fields must be completed for clarity.

For further information on the points included in this form, see Reporting Life Sciences Research. For further information on Nature Research policies, including our data availability policy, see Authors \& Referees and the Editorial Policy Checklist.

\section{- Experimental design}

\section{Sample size}

Describe how sample size was determined.

2. Data exclusions

Describe any data exclusions.

\section{Replication}

Describe whether the experimental findings were reliably reproduced.

\section{Randomization}

Describe how samples/organisms/participants were allocated into experimental groups.

5. Blinding

Describe whether the investigators were blinded to group allocation during data collection and/or analysis.
Sample sizes differ throughout as detailed in the Supplementary Notes, Table 1. Sample sizes were determined based on field availability/opportunity, and are provided in each case as an exact sample size (n).

\begin{abstract}
As reported in the text
"Originally, nine loci were genotyped, but one locus showed a significant deficiency of heterozygotes compared with expected Hardy-Weinberg Equilibrium, most likely due to null alleles, and was discarded from further analyses."
\end{abstract}

NA

NA

NA

Note: all studies involving animals and/or human research participants must disclose whether blinding and randomization were used.

\section{Statistical parameters}

For all figures and tables that use statistical methods, confirm that the following items are present in relevant figure legends (or in the Methods section if additional space is needed).

n/a $\mid$ Confirmed

\The exact sample size $(n)$ for each experimental group/condition, given as a discrete number and unit of measurement (animals, litters, cultures, etc.)

$\triangle$ A description of how samples were collected, noting whether measurements were taken from distinct samples or whether the same sample was measured repeatedly

X $\square$ A statement indicating how many times each experiment was replicated

$\varnothing$ The statistical test(s) used and whether they are one- or two-sided (note: only common tests should be described solely by name; more

complex techniques should be described in the Methods section)

$\bigotimes$ A description of any assumptions or corrections, such as an adjustment for multiple comparisons

$\square$ \ The test results (e.g. $P$ values) given as exact values whenever possible and with confidence intervals noted

Х $\square$ A clear description of statistics including central tendency (e.g. median, mean) and variation (e.g. standard deviation, interquartile range) $\bigotimes \square$ Clearly defined error bars 
Policy information about availability of computer code

\section{Software}

Describe the software used to analyze the data in this study.

SigmaPlotv11.0, CERVUSv3.0.3, MICRO-CHECKERV2.2.3, COANCESTRYv1.0.1.5, COLONYV2.0.1.9

For manuscripts utilizing custom algorithms or software that are central to the paper but not yet described in the published literature, software must be made available to editors and reviewers upon request. We strongly encourage code deposition in a community repository (e.g. GitHub). Nature Methods guidance for providing algorithms and software for publication provides further information on this topic.

\section{- Materials and reagents}

Policy information about availability of materials

\section{Materials availability}

Indicate whether there are restrictions on availability of unique materials or if these materials are only available for distribution by a for-profit company.

\section{Antibodies}

Describe the antibodies used and how they were validated for use in the system under study (i.e. assay and species).

10. Eukaryotic cell lines

a. State the source of each eukaryotic cell line used.

b. Describe the method of cell line authentication used.

c. Report whether the cell lines were tested for mycoplasma contamination.

d. If any of the cell lines used are listed in the database of commonly misidentified cell lines maintained by ICLAC, provide a scientific rationale for their use.

\section{NA}

NA

\section{- Animals and human research participants}

Policy information about studies involving animals; when reporting animal research, follow the ARRIVE guidelines

11. Description of research animals

Provide details on animals and/or animal-derived materials used in the study.

NA

Policy information about studies involving human research participants

\section{Description of human research participants}

Describe the covariate-relevant population

characteristics of the human research participants. 